\title{
Solving multidimensional problems through a new perspective: The integration of design for sustainability and engineering education
}

\author{
Ryan Legg, Mark Tekippe, Krishna S. Athreya, Mani Mina \\ Iowa State University, Ames, Iowa
}

This paper introduces the concepts and premises of design for global sustainability and its integration into engineering education. Since the main premise of engineering is "design with constraint," the integration of global sustainability concepts and requirements will offer multidimensional constraints that will enrich the challenges and benefits of engineering. Design for sustainability is a new interdisciplinary approach to engineering, which combines traditional engineering, science, sociology, business, etc, into a true multidimensional interdisciplinary platform for effective problem solving. We will introduce the concepts, applications, and examples of such efforts in engineering education and present some important case studies. We will discuss and demonstrate the effectiveness of this approach to engineering problem solving in providing a more comprehensive education to our prospective professional engineers and world citizens. Sustainable design integrated with modern engineering practices will revolutionize the engineering profession through education, and prepare engineers and engineering students for the coming challenges of the 21st century.

\section{Introduction}

Engineering as a profession exists to benefit humanity through technological innovation. Engineers are thus implicated in a responsibility to develop solutions and innovations in a manner that avoids introducing new problems to the world. Today, advances in information technology, transportation, and supply chain management are supporting an increasingly interconnected global community. In order to continue to create optimal solutions, engineers must, from the very beginning, recognize the global community and incorporate a global perspective in design. A socially responsible engineer in the world today must operate with a global perspective and leverage innovative ideas that cross disciplinary boundaries.

A new perspective is required to educate the engineering student of today to approach design challenges in a holistic manner; which ensures long term impacts of designs are well researched and addressed. Because engineers will be designing for a global community, engineering students must be able to identify the multiple effects of their practice around the world. Engineering education should use globalization as a driver to help students become more connected with the world and other professions, and to ensure that as practicing engineers they will provide the best possible solutions for the context of a problem. Currently, our education system does not adequately prepare future engineers to address challenges on this scale. Engineering students graduate from the educational arena into a global community with insufficient education about either the scope or long-term impact of the problems and solutions

"Proceedings of the 2005 American Society for Engineering Education Annual Conference \& Exposition Copyright (C 2005, American Society for Engineering Education” 
they will face. Students receive extensive training on problems within their specific technical field, but often have minimal opportunity to investigate alternative approaches to complex problems. Students are also not often challenged to account for the long-term environmental or social impacts of technological solutions in the more complex situations they will operate in upon leaving academia.

These issues and others have motivated many within the community of engineers to bring up the need for reform in engineering education. Reform ideas have appeared in the reports of the American Society of Engineering Education in $1994^{1}$, National Research Council in $1995^{2}$ and the National Science Foundation in $1995^{3}$. The integration of sustainable design concepts into engineering education teaches for an interdisciplinary, holistic approach to engineering problems to provide better designs in practice. Designing for sustainability forces students to consider and react to problems and constraints beyond their field of specialization and integrate new life-cycle issues into technical design. The resulting changes to engineering problem solving perspective and approach will reform engineering education to enhance the compassionate, creative, and collaborative drive of its graduates.

\section{Sustainability and Sustainable Design}

Theoretically, sustainability is a fairly simple concept. In order to be sustainable, a solution must be able to be kept in existence and maintained while remaining useful. However, not surprisingly, complexities arise when sustainability is incorporated into technical design. Sustainable design requires a multifaceted problem solving perspective to provide solutions driven not merely by the limits of current technology, but also by the minimization or elimination of both short and long-term adverse effects on the environment or society. The constraints of this new problem set include, among others, environmental impact, operations and maintenance, cultural appropriateness, economic feasibility, and life cycle analysis.

Engineers are readily familiar with and accept the definition of engineering as "design under constraint”" . Engineers identify and work within constraints to create an optimal technical solution. Sustainable solutions, however, reach beyond the technical solution and require a sophisticated understanding of non-technical constraints. Engineering graduates who understand and value environmental, economic, and cultural systems, can create effective sustainable designs for current and future challenges. ${ }^{5}$

\section{Environmental Sustainability}

Environmental impact is increasingly coming to the forefront in the creation and use of new products. Environmental sustainability means going beyond existing regulatory constraints. The process of creating environmentally sustainable design solutions must begin at product selection and, ideally, end at the recycling or reuse of all product components used in design. Strategies such as Pollution Prevention, product stewardship, life-cycle analysis, and the creation of clean technologies through bioengineering and Bio-mimicry ${ }^{6}$ can be applied to all engineering solutions. ${ }^{7}$ Engineers must begin to evaluate not only their solutions, but also the supply chain and production manufacture of engineering materials and processes. A true Cradle to Cradle ${ }^{8}$ 
approach to product selection and use is needed to not only minimize adverse environmental impact, but also eliminate it altogether.

The use of new eco-efficient materials, processes, and engineering solutions will undoubtedly have an impact on our standard of living worldwide. By designing solutions to be environmentally sustainable, engineers will be providing scalable solutions that can be implemented in a variety of situations. Minimal additional effort would be needed to meet local regulations because a sustainable design would have, by default, already exceeded those regulations.

\section{Economic Sustainability}

Sustainability also implies that a solution or design will be economically beneficial when implemented. Without economic motivation, businesses will be reluctant to expend resources to create new sustainable products. However, the current paradigm of product creation for profit does little to consider the economic effects of the end of a product's life cycle. The paradigm also ignores the collective economic power of the majority of the world's population who are individually insignificant in terms of their resource utilization.

A product's current 'useful life' is often used to define the time period beyond which the user will eventually discard, renovate, or remodel a product. Economic sustainability changes the end of the 'useful life' ideology and promotes design solutions that can be used for multiple purposes. In order to create solutions with multiple life-cycles, potential future uses must be considered at the front end of the design process. The revolutionary GAP headquarters designed by architect, William McDonough, illustrates the integration of sustainable design in the creation of an office complex in San Bruno, California ${ }^{9}$. McDonough's design focused on the idea that GAP could sell the building as a multi-family dwelling with little alteration to the building itself once GAP had exhausted its 'useful life' of the building. Thus, the building was not designed for merely one useful life, and will prove to be profitable for the owner upon the beginning of its second 'useful life'.

Engineering innovation cannot only generate economic sustainability, but can actually drive a new model for economic development. Natural Capitalism ${ }^{10}$ highlights an economic shift in the industrialized world based around creation of jobs and economies for conservation of the environment and ultimately, sustainability. Additionally, creation of new technologies within the social constraints of the underdeveloped world can act as an economic driver for businesses to create products for the nearly four billion people in the developing world who currently cannot afford them. Inclusion of the "Base of the Pyramid" in product development and design will, in turn, create a more sustainable consumer base for producers and extend engineering's reach into economic development business strategies for sustainable development. ${ }^{11}$

\section{Social Sustainability}

Sustainable engineering also incorporates several aspects of social engineering - a fundamental design component that can be overlooked in contemporary engineering practice. Sustainable design requires engineers to be sensitive to the many obstacles that reside beyond the technical

"Proceedings of the 2005 American Society for Engineering Education Annual Conference \& Exposition Copyright C 2005, American Society for Engineering Education” 
level, within the social bounds of a problem. This new social awareness forces engineers to evaluate the much wider social and cultural setting for their design decisions and optimize the transition from theory to practice. A simple case study in Belize reveals the significance of social consciousness in engineering designs.

Driven by the need for improved water access and purification in a Belize village, a group of engineers devised a plan for centrally located water source to replace the existing cumbersome system of getting water. This new system would eliminate the need for village women to make lengthy daily trips to the river for laundry and water collection for domestic use. Although the solution was appropriately evaluated in terms of efficiency, a lack of cultural understanding by the engineers led to devastating social results. Even with the solution installed, the village women still preferred traveling to external water sources because they were able to use this time for social bonding. As a result, many village women refused to use the new facilities. The women that did take advantage of the proximity suffered other effects. The modern facilities were segmented into small, secluded rooms for showering and laundry. The increased time women spent near their homes, combined with the culture's limitations to privacy provoked an increase in domestic battery. ${ }^{12}$ Thus, by solving the problem on a technical level and employing the western cultural value of time-saving efficiency, the engineer's solution generated profound social impacts.

The overachieving goal of any engineering solution is the improvement of quality of life. Alleviating technical problems at the cost of creating new social problems does not constitute good engineering. A sustainable design approach must focus on minimizing negative social impacts to allow a solution to be effective throughout its useful life. Engineers trained with an emphasis on sustainability in design will approach problem solving with non-technical constraints, like social engineering at the forefront of their design.

Integrating sustainable design concepts into engineering education allows engineering students to develop skills that extend beyond the scope of a traditional engineering curriculum by adding a global perspective. Using this new perspective, engineers are able to establish a problem-solving platform that incorporates the multidisciplinary approach necessary to provide the most effective solutions.

\section{Sustainability in Engineering Education}

An emphasis on sustainability in design will catalyze a change in engineering education so that students will approach design with a multidisciplinary, global perspective. This approach will be used to solve problems around the world and further connect students and their University to the world. Current ABET accreditation criteria ${ }^{13}$ requires emphasis on teamwork and an interdisciplinary understanding of the societal, ecological, financial, national and global

impacts of engineering. ${ }^{5,14}$ An engineering curriculum that incorporates sustainable design, will keep students technically sound, while also creating a platform for engineering students and professionals to interact and create partnerships with other disciplines, universities and societies. ${ }^{15}$

"Proceedings of the 2005 American Society for Engineering Education Annual Conference \& Exposition Copyright @ 2005, American Society for Engineering Education” 
Education that emphasizes a sense of global connectedness creates a learner-centered environment where students are encouraged to collaborate with communities in various parts of the world for both problem definition and solution design. The cooperative efforts with create solutions that can be adapted throughout the global community. Thus, flexibility and scalability are factors in the forefront of design. Considering issues of scalability and social context to ensure ideal solutions can lead to real innovative solutions and result in a sense of fulfillment for the students in terms of the social impact of their work. Designs of this nature occur in an environment of educational exchange that bridges engineering coursework with other academic fields. ${ }^{4}$ Learning prompted by questions of local sustainability encourage student involvement in the challenges and values of design trade-off. Ultimately issues of scalability will ease the transition of engineering technology from conceptual research to implemented practice.

The effects of this new learning environment will promote further creativity and interdisciplinary understanding in engineering. Partnerships within and beyond the university will promote creativity by further bringing together differing views, approaches, and perspectives. Without a diversity of collaborators and their unique viewpoints, we limit the possibilities. As eloquently stated by Wm. A. Wulf, without diversity there is a lost opportunity cost, a cost in products not built, in designs not considered, constraints not understood, in processes not invented ${ }^{16}$ This also holds true for the engineering curriculum. Researching and designing with a global perspective, including an understanding of technical, social and environmental impact will create a more marketable and adaptable engineering graduate. This "new graduate" will not merely keep pace with global competition and restructuring of industry as it occurs during their lifetime, but will drive industry changes. Hence, not only will the integration of sustainable design in engineering education improve academia it will also act as a catalyst for paradigm shift in the profession as a whole.

\section{Integration Attempts}

The idea of sustainability, and more specifically sustainable development, is infiltrating the engineering curriculum at several universities throughout the United States allowing students to confront sustainable design issues from the early stages of their engineering undergraduate studies. Existing sustainability programs include support for student organizations, learning communities, course offerings, design and research based curriculum additions, and blanket curriculum changes. Such programs are experiencing great student enthusiasm and witnessing tremendous impacts on students' education in and out of the classroom.

At Iowa State University, the College of Engineering has shown support for the student chapter of Engineers for a Sustainable World ${ }^{17}$ (ESW-ISU) since its inception in August 2003. The college has fostered the student organization's growth and provided funding for student project assessment trips, national conference visits, and leadership development. The college's support greatly increased the student organization's visibility to the University and the surrounding community as well as provided new avenues for undergraduate involvement in university extension. At Cornell University, the student chapter of Engineers for a Sustainable World was able to begin a course offering: "CEE 492: Engineers for a Sustainable World"18 in 2003 as a design course for all majors. The course allows students to design and implement sustainable projects in developing countries in collaboration with the Cornell student chapter, and with local

"Proceedings of the 2005 American Society for Engineering Education Annual Conference \& Exposition Copyright (C 2005, American Society for Engineering Education” 
and international non-governmental organizations and university partnerships. ${ }^{19}$ The course has also acted to diversify the engineering program at Cornell; since inception, the course has welcomed students from nine different departments, freshman through master's candidates, and,

in its four semester of existence, $55 \%$ of the students taking the course have been female. ${ }^{20}$

Pennsylvania State University (PSU) began a course offering in 2003 as well and has since extended the breadth of the program by instituting courses to allow students without the technical background for engineering design to become involved in the social, political and project assessment aspects. A series of one credit courses were established with emphasis on project development elements including: establishment of university memoranda of understanding, formation of collaborative teams, problem identification and client need assessment, background research and preliminary study production. Courses lead to a 3 credit design/research course including project specific elements of fundraising, proposal writing, and implementation planning.

PSU has furthered their mission to recruit and retain students by creating a learning community and holding awareness-raising functions around luncheons, social and educational activities and outside the classroom hands-on training and skill development. Skill outcomes of the program include: Adaptability, leadership, lifelong learning, self-development, and information and technology literacy. These skills were also identified and sought after by PSU industry partners as "transferable" skills into the private sector. ${ }^{21}$

\section{Conclusion}

The traditional engineering curriculum does not adequately address the fundamental nontechnical issues involved in creating optimal solutions. As traditional constraints of geography and communication are weakened, the context for engineering design is changing and a global approach to engineering problem solving and innovation is key. Engineering education needs to accommodate curriculum changes to ensure that engineers approach problems with adequate insight into the implications of solutions for which they are responsible. Sustainability, as a design process, will promote a more holistic approach to design problems of constraint and context and will create better, more workable solutions for the current and future world community. Issues of sustainable design integrated with modern engineering technology ensures a dynamic and vibrant engineering education to better prepare engineers and engineering students for the coming challenges of the $21^{\text {st }}$ century.

\section{Bibliography}

1. American Society of Engineering Education (ASEE). Engineering for a Changing World. ASEE. 1994.

2. National Research Council. Engineering Education: Designing as Adaptive System. Board on Engineering Education. Washington, DC: National Academy Press. 1995.

3. National Science Foundation (NSF). Restructuring Engineering Education: A Focus on Change. Report of an NSF Workshop on Engineering Education, June 6, 1994. NSF 95-65. Arlington, VA. 1995.

4. Wulf. Wm. A. The Urgency of Engineering Education Reform. The Bridge, 1998.

"Proceedings of the 2005 American Society for Engineering Education Annual Conference \& Exposition Copyright (O) 2005, American Society for Engineering Education” 
5. Splitt, Frank G. Environmentally Smart Engineering Education: A Brief on a Paradigm in Progress. ASEE Journal of Engineering Education Vol. 91, No. 4, October 2002: 447-450.

6. Benyus, Janine M. Biomimicry. New York: HarperCollins Publishers Inc, 2002.

7. Hart, Stuart L. Beyond Greening: Strategies for a Sustainable World. Harvard Business Review. JanuaryFebruary 1997: 67-76.

8. McDonough, William and Braungart, Michael. Cradle to Cradle. New York: North Point Press, 2002.

9. McDonough, William. Taken from Keynote Address at the Engineers for a Sustainable World National Conference. September 30, 2004.

10. Hawken, Paul, Lovins, Amory, and L. Hunter Lovins. Natural Capitalism: Creating the Next Industrial Revolution. Rocky Mountain Institute, 1999.

11. Hart, Stuart L. and Christensen, Clayton M. The Great Leap: Driving Innovation From the Base of the Pyramid. MIT Sloan Management Review, Fall 2002: 51-56.

12. McClusky, Laura. Belize Basics. Presentation at Engineers Without Frontiers National Conference 2003. September 19, 2003.

13. Engineering Accreditation Commission. Criteria for Accrediting Engineering Programs (Effective for Evaluations During the 2005-2006 Accreditation Cycle). ABET. Baltimore, MD. November 1, 2004.

14. Splitt, Frank G. Systemic Engineering Education Reform: A Grand Challenge. The Bent of Tau Beta Pi, Spring 2003: 29-34.

15. Splitt. Frank G. The Challenge to Change: On Realizing the New Paradigm for Engineering Education. Engineering Education Reform: A Trilogy. Submitted for publication in the ASEE Journal of Engineering Education. October 2002.

16. Wulf, Wm. A. Diversity in Engineering. Remarks given October 4, 1998 at the NAE Annual Meeting.

17. www.esustainableworld.org.

18. http://ceeserver.cee.cornell.edu/esw/course_pages/course.htm.

19. Grose, Thomas A. Engineering Students are Traveling Far and Wide to Improve the Lot of Some of the World's Poorest Communities. http://www.prism-magazine.org/sept04/a_world_class_act.htm. 2004.

20. Weber-Shirk, Monroe L. Cornell's ESW Project Course. Presentation at the Engineers for a Sustainable World National Conference. October 2, 2004.

21. The Penn State Model. Presentation at the Engineers for a Sustainable World National Conference. October 2, 2004.

RYAN LEGG graduated (Dec04) from Iowa State University with a Bachelor's of Science degree in Civil Engineering. He is Founder and President of the Iowa State University chapter of Engineers for a Sustainable World he worked to integrate sustainability into the curriculum. He is currently working for Opus West Construction Corporation as an Associate Project Manager in Pleasanton, California.

MANI MINA is an adjunct assistant professor in electrical and computer engineering and the director of Spacecraft Systems and Operation Laboratory (SSOL) at Iowa State University. He has been a recipient of several teaching and research awards. His research interests include physical layer measurements and testing, optical networking, nondestructive testing and evaluation, and innovative methods of teaching technology.

"Proceedings of the 2005 American Society for Engineering Education Annual Conference \& Exposition Copyright @ 2005, American Society for Engineering Education” 